\title{
Nigrospora sphaerica (Saccardo) E.W. Mason Pathogenic to Cajanus cajan L - First Report from India
}

\author{
Aarti M. Patil, Sadat M. Quazi and Seema M. Sathe*
}

Department of Botany, Maulana Azad College, Aurangabad (MH), India

*Corresponding author

\section{A B S T R A C T}

Keywords

N.sphaerica, Infection, Firstly, Cajanus cajan L.

\section{Article Info}

Accepted:

17 October 2020

Available Online:

10 November 2020
Nigrospora sphaerica (Sacc.) Mason. found to infect leaves of Cajanus cajan L. in the Marathwada region of Maharashtra, India is a new host record. Symptoms on leaves appeared in the form of semi circular to irregular, grey to black coloured spots. Based on morphological, cultural and molecular study. The fungus isolated was identified as Nigrospora sphaerica Mason. Pathogenecity test of the fungus was confirmed as per Koch's postulates.

\section{Introduction}

Cajanus cajan L. is a perennial leguminous shrub that belongs to family Fabaceae. The height of the plant reaches upto 1-5 meters and life span of the plant is about five years (www.onlyfoods.net)/pigeon-peas.hmtl). It is also called as tur, arhar, red gram (Ghadge et $a l ., 2008)$. Pigeon pea is an economically and nutritionally important pulse crop plant serving as a major protein source for the population of the world (Singh et al., 1984). A leaf spot disease was observed on plant Cajanus cajan L. growing in Aurangabad, Maharashtra, India during a survey of fungal disease along with many disease of pigeon pea. The present research describes and illustrates the disease causing pathogen in detail.

\section{Materials and Methods}

\section{Survey of the disease}

A survey was carried out during Aug 2017 to Dec 2017 to study fungal diseases of pigeon pea. The diseases were studied by observing their symptoms on the plant. The survey was repeated three times.

\section{Isolation and morphological identification}

Infected leaf samples were collected from different fields in Aurangabad district of 
Marathwada region of Maharashtra, India. The infected leaves were surface sterilized with sodium hypochlorite solution and subsequently washed three to four times with sterilized distilled water and were transferred aseptically to PDA (Potato Dextrose Agar), containing streptomycin as antibacterial agent. The growth of the fungal colony was observed for seven days in BOD incubator as well as morphological and cultural characters of the fungus were studied. A microscopic examination of the fungus was carried out by mounting on slide and the fungus was morphologically identified using standard taxonomic keys (Barnett and Hunter).

\section{Molecular identification}

It involves isolation of fungal DNA for which fungal dried mats were employed. Fungal DNA was isolated using CTAB method (Modified Doyle and Doyle, 1990) followed by amplification of its region by PCR using a primer pair ITS4: TCCTCCGCTTATTGATATGC and ITS5: GGAAGTAAAAGTCGTAACAAGG. The PCR product was purified and processed for cycle sequencing and reaction was made by using Big Dye R Terminator V.3.1 Cycle sequencing kit (Applied Bios stem, Inc.) with $16^{\text {th }}$ fold dilution. Sequence obtained for Co-I were aligned and assembled in codon code aligner v 4.0.3 (Codon code, Dedham, MA, USA) using Muscle Algorithm and Mega 5 (Tamura et al, 2011) Using Clustal Walgorithm. The sequence was blast on BOLD Systems (Barcode of Life Data System) and NCBI (National Center for Biological Information) and species name was assigned by matching query coverage above $97 \%$. Using molecular analyses a neighbor joining tree or phylogenetic tree (Saitour and Nei, 1987) of k2P distances were created using Mega 5 (Tamura et al., 2011). Cases leading to uncertain identifications were resolved using the Automatic Barcode Gap
Discovery (ABGD) tool web interface (http://www.abi.snv.jussieu.fr/publicla).

\section{Pathogenecity test}

The healthy leaves were taken and surface sterilized with 0-5\% Sodium hypochlorite and distilled water and were injured aseptically. The injured places on the leaves were inoculated with the isolated fungus and the leaves were incubated for seven days with the adjusted humidity to observe symptoms of disease. In this way, pathogenicity test was carried out as per Koch's postulates.

\section{Results and Discussion}

\section{Morphological and molecular identification of the isolated fungus from pigeon pea}

Nigrospora sphaerica was isolated from the infection of Cajanus cajan L. by leaf spot disease. The symptoms produced by the disease were circular to irregular, grey to black colored spots that varied in size. The infected part of leaves was inoculated repeatedly, that isolated same fungus every time. The fungus grown profusely on PDA. Initially the colony was white which later changed to light and dark grey. The colony was raised, cottony (Fig. 1).

They grey colored pigmentation to colony may be due to abundance sporulation. The spore was a single celled conidium that was spherical and brownish black in colour borne on hyaline vesicle at the apex of the conidiophores. The description of the isolated fungus was compared with the description in the standard taxonomic keys (Barnett and Hunter) and it was identified as Nigrospora sphaerica (Saccardo) E.W. Mason. The molecular identification of the fungus was based on the sequence analysis of (ITS) region of rDNA of the isolated fungus with the universal primers ITS 4 and ITS 5. 
The DNA sequence of the isolated fungus in fasta format

$>$ APF5

AGTAAAAGTCGTAACAAGGTCTCCGTT GGTGAACCAGCGGAGGGATCATTACA GAGTTATCCAACTCCCAAACCCATGTG AACATATCTCTTTGTTGCCTCGGCGCA AGCTACCCGGGACCTCGCGCCCCGGGC GGCCCGCCGGCGGACAAACCAAACTC TGTTATCTTCGTTGATTATCTGAGTGTC TTATTTAATAAGTCAAAACTTTCAACA ACGGATCTCTTGGTTCTGGCATCGATG AAGAACGCAGCGAAATGCGATAAGTA ATGTGAATTGCAGAATTCAGTGAATCA TCGAATCTTTGAACGCACATTGCGCCC ATTAGTATTCTAGTGGGCATGCCTGTT CGAGCGTCATTTCAACCCCTAAGCACA GCTTATTGTTGGGCGTCTACGTCTGTA GTGCCTCAAAGACATTGGCGGAGCGG CAGCAGTCCTCTGAGCGTAGTAATTCT
TTATCTCGCTTCTGTTAGGCGCTGCCCC CCCGGCCGTAAAACCCCCAATTTTCTG GTGACC

By molecular identification, the identity of the fungus Nigrospora sphaerica (Saccardo) E. W. Mason was confirmed. The sequence was submitted to NCBI and its accession number is MN121557.

\section{Pathogenecity test}

As per the Koch's postulates, pathogenecity of the fungus was tested that resulted in the appearance of the symptoms of the disease as the original ones. Hence, the fungus was confirmed as a true pathogen for Cajanus cajan $\mathrm{L}$. The fungus was reisolated from the resulted symptoms and its pathogenic identification was confirmed.

Fig.1 Morphological and cultural features of Nigrospora sphaerica Mason

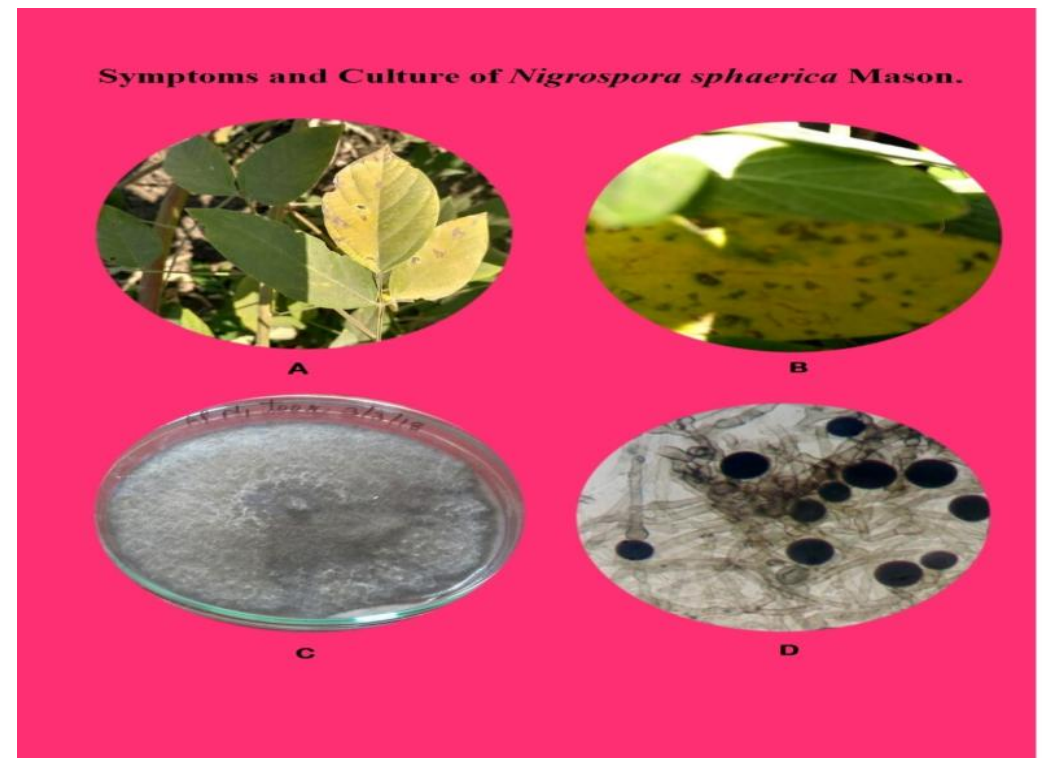

Nigrospora sphaerica was recorded as a pathogen for several hosts such as kiwi fruit (1) date palm (2) Celtis australis (3 Kinnow mandarin (4) and many others but it has not been previously reported on Cajanus cajan L. and to the best of my knowledge and literature survey it is a first report from Aurangabad Dist. of Marathwada region of Maharashtra and India. 


\section{Acknowledgment}

The author is thankful to Department of Botany, Maulana Azad College, and Aurangabad (MH) for providing necessary facilities to carry out research. The author is also thankful to UGC for providing fund in the form of Maulana Azad National Fellowship during research.

\section{References}

Ajay Kumar Gautam. 2015. First report of Nigrospora sphaerica causing leaf spots on Celtis australis from Himachal Pradesh, India. International Letters of Natural Sciences, Vol. 40, Pp. 16-18.

Doyle, J.J.; Doyle J. I.1990. Isolation of plant DNA from fresh. Focus, V. 12, p. 1315.

http://wwwabi.snv.jussieu.fr/public/a

L.Li H. Pan Y.F. Liv, D.W.Li, Q. Zhang, L. Deng, M.Y. Chen, and C.H. Zhong. 2018. First report of Nigrospora sphaerica causing kiwifruit Postharvest Rot Disease in China. Plant Disease Vol. 102, No. 8. ISSN: 0191-291 eISSN: 1943-7692.

M.W. Alarm, A. Rehman, M.L. Gleason, k. Riaz, M. Saira, A. Aslam, H. Rosli and
S. Muhammed. 2017. First report on Nigrospora sphaerica causing leaf sport of Kinnow mandarin in Pakistan. Journal of Plant Pathology, 99 (1), 287304.

Mohammed H. Abass and Najlaa $H$. Mohammed. 2014. Morphological, Molecular and Pathological Study on Nigrospora oryzae and Nigrospora sphaerica, the leaf spot fungi of date palm. Basra Journal for Date Palm Research, Vol. 13, No. 1-2.

Mohammed H. Abass, Muhammed A. Hameed and Alaa Naser Ahmed. 2013. First report of Nigrospora sphaerica (Sacc.) Mason as a potential pathogen on date palm (Phoenix dactylifera $\mathrm{L}$.) Canadian Journal of Plant Pathology, 35:1, 75-80, Moi: $\quad 10$ 1080/07060661.2012 702612.

Saitou N, Nei M. 1987. The Neighbour Joining method: A new method for reconstructing phylogenetic trees. Mol Biol Evol 4: 406-425.

Tamur K. Peterson D, Peterson N, Stecher G, Neim, Kumar S. 2011. MEGA5: Molecular evolutionary genetics analysis using maximum likelihood, evolutionary distance and maximum parsimony methods. Mol Biol Evol. 28: 2731-2739.

\section{How to cite this article:}

Aarti M. Patil, Sadat M. Quazi and Seema M. Sathe. 2020. Nigrospora sphaerica (Saccardo) E.W. Mason Pathogenic to Cajanus cajan L - First Report from India. Int.J.Curr.Microbiol.App.Sci. 9(11): 2414-2417. doi: https://doi.org/10.20546/ijcmas.2020.911.290 